\title{
Emerging nanoparticulate systems: Preparation techniques and stimuli responsive release characteristics
}

\author{
Shailja Jain\$, Saravan Krishna Cherukupalli, Arisha Mahmood, Srividya Gorantla, Vamshi Krishna Rapalli, Sunil Kumar \\ Dubey, Gautam Singhvi* \\ Department of Pharmacy, Birla Institute of Technology and Science, Pilani, Rajasthan, India.
}

\begin{tabular}{l}
\hline ARTICLE INFO \\
\hline Received on: 29/03/2019 \\
Accepted on: 27/06/2019 \\
Available online: 03/08/2019 \\
\\
\hline Key words: \\
Nanoparticles, in situ, \\
self-assembled nanoparticles, \\
nanoprecipitation, \\
stimuli-responsive drug \\
release.
\end{tabular}

\begin{abstract}
Nanotechnology has become an outgrowing field in novel drug delivery system. It confers several merits over conventional formulations like increased solubility and bioavailability, targeted drug delivery and a decreased dose of the drug. The selection of appropriate method for the preparation of nanoparticulate system depends on the physicochemical characteristics of the drug to be loaded and polymer. This review has covered the most widely acceptable preparation techniques for polymeric and lipidic nanoparticles including nanoprecipitation, milling, extrusion, supercritical fluid technology, salting out, gelation, sonication, high-pressure homogenization, and solvent emulsification methods. Nanocarriers, the traditional nano-formulation drug delivery systems, encountered some major problems in process scale-up, reproducibility, and stability during storage. To circumvent these problems a new approach has emerged which are "In situ or self-assembled nanoparticles drug delivery system." Such approaches comprise experimentation with different types of polymers, surfactants or novel process in order to prepare a preconcentrate of drug formulation, which on entering into an aqueous medium (gastrointestinal fluid, blood) will form nanoparticles. The in situ nanoformulations can be the futuristic approach in nanocarriers to overcome the problems associated with the scale-up process and also minimize the cost of production. This review focuses on different preparation techniques for polymeric and lipidic nanocarriers preparation, in situ nanoformulation approaches and release characteristics of stimuli responsive nanoformulation.
\end{abstract}

\section{INTRODUCTION}

Commercially available conventional dosage forms are lacking for targeting the drug delivery and have a plethora of formulation problems. Many attempts have been made over a few decades in order to develop newer drug delivery systems that can overcome the problems faced by the existing dosage forms. Along with this, researchers were also trying to incorporate multidisciplinary scientific approaches to improve the drug's physicochemical limitations, bioavailability issues, site-specific delivery, and stability in the microenvironment. Additionally,

\section{*Corresponding Author}

Gautam Singhvi, Department of Pharmacy, Birla Institute of Technology and Science, Pilani, Rajasthan, India.

E-mail: gautam.singhvi@pilani.bits-pilani.ac.in

${ }^{s}$ Both authors contributed equally. efforts were made for preventing the dose dumping by controlling the release profile, reduced exposure of the drug to non-targeting tissues, increasing safety profile, and minimizing the toxicity and side effects.

Nanotechnology has driven drug delivery approaches to improve the existing issues of conventional drug delivery systems. Nanocarriers including natural and synthetic polymeric nanoparticles, metal nanoparticles, liposomes, transferosomes, ethosomes, niosomes, virosomes, cochleate, cubosomes, solid lipid nanoparticles (SLN), nanostructured lipid carriers (NLC), lyotropic liquid crystalline nanoparticles, microemulsions, nanoemulsions, and quantum dots have been investigated for various disease conditions with numerous drug candidates (Girdhar et al., 2018; Martinho et al., 2011; Safari and Zarnegar, 2014; Singhvi et al., 2018).

Nanoparticles are materials with overall dimensions in the nanoscale, i.e., under 10 to $1,000 \mathrm{~nm}$. From a few decades, it is found that these materials have emerged their multifunctional 
role in drug delivery with clinical applications which range from diagnostic agents in imaging to carriers for drug delivery and gene delivery into cancerous cells (Dua et al., 2018; Khosa et al., 2018).

Nanocarriers have been proved effective compared to the conventional approach for targeting the drug candidate to specific organ or tissue. Nanocarriers have been extensively investigated for cancer targeting, central nervous system targeting, tuberculosis, psoriasis, diabetes, Alzheimer, and neurodegenerative diseases (Dua et al., 2018a; Rapalli et al., 2018).

Due to small size, alteration in surface charge, utilization of penetration enhancers like cell penetrating peptides, nanocarrier-based formulations have been proved as an effective treatment strategy for these diseases. Nanoparticulate systems can be modified to target the site of action, which can improve the efficacy of drugs and minimize the toxic effect of therapeutic agents (Dua et al., 2019).

Along with these advantages, nanoparticles have certain limitations pertaining to environmental and societal challenges, mainly in concern to toxicity (Murthy, 2007).

Advantages of nano drug delivery system as follows:

1. Stability of volatile pharmaceutical agents increases.

2. Increase in safety and efficacy compared to conventional drug delivery system.

3. Targeted drug delivery to a specific site of action.

4. Reduced drug resistance.

5. Reduction in particle size enhances the solubility of the drug.

6. The dissolution rate of the formulation increases.

7. Bioavailability of the drug increases.

8. Different types of drug release rates can be achieved.

9. Inter-patient variability decreases.

10. Increase in the stability of poorly stable drugs.

11. Rapid onset of action can be achieved.

12. A low dose of the drug is required to be administered as drug concentration in the targeted tissue is more.

13. Toxic profile of the drug is compromised as dose administered is less.
Polymeric nanoparticles are used for targeted drug delivery with the utilization of various polymers. Polymers are classified into natural and synthetic polymers (Couvreur, 2013). Naturally occurring biopolymers such as cellulose, chitosan, dextrin, albumin, alginate, and gums have numerous advantages over synthetic substances in terms of biocompatibility, biodegradability, and low immunogenicity (Kumar et al., 2016). Polymer-based nanoparticles have some drawbacks such as poor drug loading, lack of process scale-up, reproducibility, and stability during storage. In order to overcome these problems, a new approach has come forward, which is "in situ or selfassembled nanoparticles drug delivery systems." This review has covered methods of preparation of traditional nanoparticles, its advantages, challenges, and attempts made to overcome these challenges. Additionally, in situ nanoformulations preparation techniques have also been discussed as a future perspective to overcome the traditional preparation methods for nanoparticles.

\section{CURRENT METHODS OF PREPARATION OF NANOPARTICLES}

Several methods for the preparation of nanoparticles were reported in the literature based on the type of materials used in the preparation, such as polymers, lipids, and metals. Some most applied preparation techniques for the polymeric and lipid nanoparticles are discussed in the following section (Paliwal et al., 2014). A compilation of widely used preparation techniques for polymeric nanoparticles and lipid-based nanocarriers systems are shown in Figure 1.

\section{Preparation of polymeric nanoparticles}

Nanoprecipitation

It is also called a solvent displacement method. This technique is developed by Fessi et al., which includes precipitation of preformed polymers (Nagavarma et al., 2012). In this technique, the polymer is dissolved in a water-miscible organic solvent like acetone and the polymer solution is diffused into the aqueous medium, which leads to the formation of colloidal suspension either in the presence or the absence of surfactant (Nagavarma et al.,

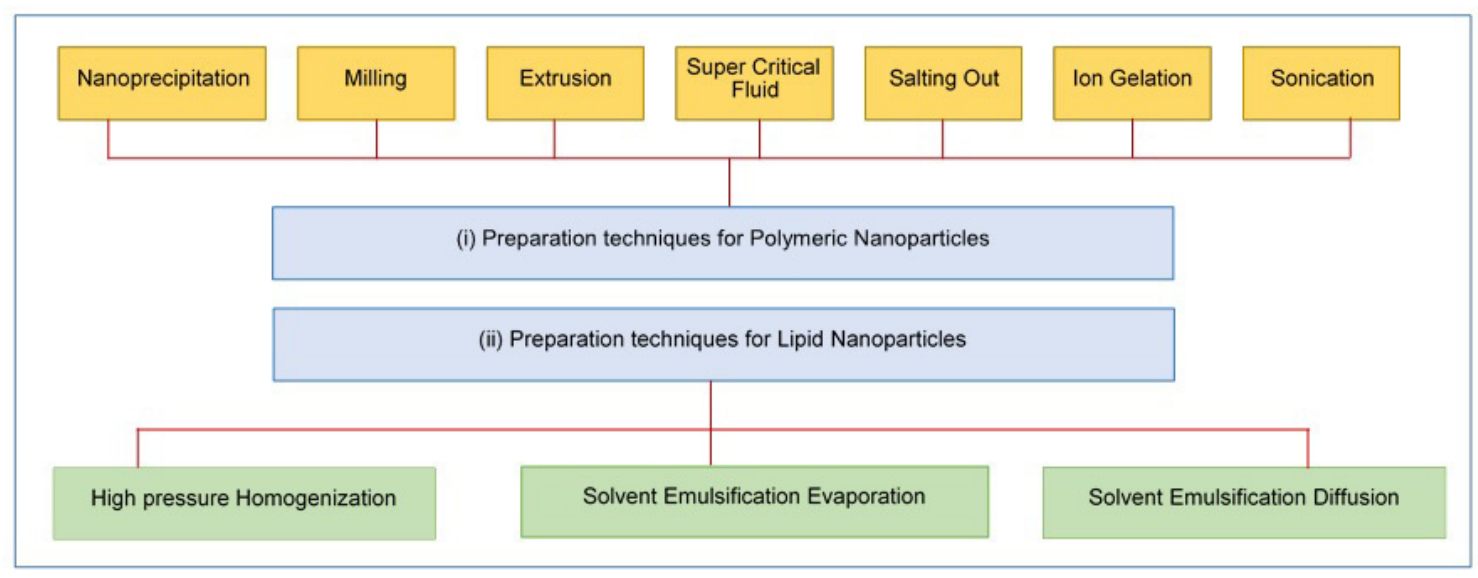

Figure 1. Compilation of widely used preparation techniques for polymeric nanoparticles and lipid-based nanocarriers systems. 
2012). The aqueous phase chosen should be miscible with the solvent and should be a non-solvent for the polymer (Loh et al., 2015). This method is appropriate for encapsulation of lipophilic drugs (water-miscible solvents) compared to hydrophilic drugs (water-immiscible solvents). In some cases, certain instability may occur when water-miscible solvents are mixed with an aqueous medium, and spontaneous emulsification is not observed. This may happen due to the higher rate of formation of coalescence by the droplets formed. When the interfacial tension between two phases is decreased, rapid diffusion occurs and small-sized droplets of organic solvents are formed, this effect is called as "Marangoni effect" (Crucho and Barros, 2017). The final particle size and the size distribution of prepared nanoparticles depend upon the nucleation and the growth kinetics which are the controlling factors for this method. The states in which the drug is present in the nanoparticles have a major impact on stability and bioavailability. To enhance the stability of nanoparticle, surfactants could be added to the preparation. Various polymers are investigated in this method, including Polylactic-co-glycolic acid 36, Polylactic acid 43, Polycaprolactone 44, and poly (methyl vinyl ethermaleic anhydride), etc. There are many processing parameters which influence the physicochemical properties of polymeric nanoparticles such as the ratio of organic phase to aqueous phase, the rate of injection of the organic phase, mixing speed, nature, and concentrations of constituents. Due to simple, quick processing, and reproducible results, this method is extensively used. However, there are many challenges for preparation of nanoparticles by means of nanoprecipitation, which include a selection of appropriate drug, solvent, and non-solvent, inefficient encapsulation of hydrophilic drugs, and problem in mixing during nanoprecipitation (Schubert et al., 2011; Xie and Smith, 2010).

\section{Milling method}

In this method, different techniques such as wet milling, milling media, high-pressure homogenization, and cryogenic milling are used for nanoparticle preparation (Loh et al., 2015). The shear force generated upon impact is the principle involved in size reduction. In wet milling, nanoparticles are produced from the drug particles suspended in liquid medium with other excipient and are milled using beads. This method is suitable for potent drugs and for drugs with high moisture content. Both organic and inorganic compounds can be used in this technology. At the end of milling, nanosuspension is produced which can be transformed into solid dosage form by granulation, freeze drying, and spray drying. Trisenox ${ }^{\circledR}$, an arsenic compound is a market preparation produced using this method (Miller et al., 2002). Media milling and high-pressure homogenization are two common top-down approaches for drug nanoparticles production without using beads. For high-pressure homogenization, two types of apparatus can be used, namely, microfluidization and piston-gap homogenization (Keck and Muller, 2006). The speed of homogenization, nature of the drug, number of cycles, and temperature control the size of nanoparticles. Due to their ease of scale-up, robust processing, economic advantages, and regulatory authority acceptance, it has become a point of research in the past decade. Some of the United States Food and Drug Administration approved products include Rapamune $^{\circledR}$, Megace ${ }^{\circledR}$, and TriCor $^{\circledR}$ that were based on media milling technique, and Triglide ${ }^{\mathrm{TM}}$ was based on high-pressure homogenization technique (Khinast et al., 2013). The size and physical stability of prepared nanoparticles depend on milling media, dispersion media, and the stabilizer used. Drawbacks of this technique include contamination of the product with the erosion of the milling material, long milling time, and scale-up problems.

\section{Extrusion method}

It is a simple method and is used to convert hydrophobic drugs into nanoparticles in a scalable and inexpensive manner (Guo et al., 2013). This technique involves the use of high pressure, shear, and heat which changes the structure of subjected compound like gelatinization, melting, and fragmentation (Song et al., 2011). This technique converts a liquid stabilized nanosuspensions into solid nanocrystals through hot-melt extrusion combined with an internal devolatilization process. In this method, water from the extruder is removed by devolatilization and polymer is solidified at the outlet. Hot melt extrusion is a continuous process in which raw material is pumped at high temperature and pressure which in turn produce uniform-sized nanoparticles (Maniruzzaman et al., 2012). This technique can be further utilized for the preparation of hydrophobic nanoparticles using the nanoporous membrane extrusion method. Nanoporous membrane extrusion includes four common strategies which are vesicle extrusion, membrane emulsification, precipitation extrusion, and biological membrane extrusion. These strategies are used in the fabrication of different nanocarriers, such as liposomes, emulsions, nanoparticles, nanotubes, and nanofibers (Guo et al., 2018). Challenges with this technique are not major but still exists like scale-up problem, the problem in nanomaterial preparation using a small amount of raw material and accumulation of raw material filtration residue at the feeding site of the channel which can block the channel easily (Roy et al., 2009).

\section{Supercritical fluid technology}

It is one of the most prominent techniques in polymeric nanoparticle production because of its advantageous processing parameters such as mild temperature conditions and avoidance of organic solvents. This technique is not only green and novel but is also useful for the enhancement of solubility of poorly soluble drugs, plasticization of polymers, surface modification, nanosizing, and nanocrystal modification and chromatographic extraction (Girotra et al., 2013). In this technique, fluid is converted into gas with the density of the liquid above its critical temperature and pressure (Sanli et al., 2012) In the preparation of nanomaterials, supercritical $\mathrm{CO}_{2}$ and $\mathrm{H}_{2} \mathrm{O}$ are extensively used. Under supercritical fluid ( $\mathrm{SCF}$ ) conditions, one can produce nanoparticles with in situ surface modification and controlled size and shape by the use of surfactants, capping agents, and templates. Alteration of surface properties from hydrophilic to hydrophobic and vice versa can be done by using appropriate capping agents (Byrappa et al., 2008; Chattopadhyay et al., 2007).

There are different methods involved in the SCF technology, they are:

1. Static supercritical fluid process

2. Rapid expansion of supercritical solutions

3. Particles from gas-saturated solutions

4. Gas anti-solvent process 
5. Precipitation from compressed anti-solvent

6. Aerosol solvent extraction system

7. Supercritical anti-solvent process

8. Solution enhanced dispersion by supercritical fluids

9. Supercritical anti-solvent process with enhanced mass transfer

10. Depressurization of an expanded liquid organic solution

11. Supercritical assisted atomization

12. Hydrothermal synthesis under supercritical conditions via flow reactor

13. Hydrothermal synthesis under supercritical conditions via batch reactor

14. Supercritical fluids drying

15. Supercritical fluid extraction emulsions

Some of the merits of this technique include control on fluid properties, reduction in viscosity, and suitability for temperature sensitive molecules. It has also some drawbacks including the requirement of high-pressure equipment which need high investment and also most of the polymers show poor solubility in SCF (Fattahi et al., 2016).

\section{Salting-out method}

This method came into existence in order to overcome the disadvantages of emulsification-solvent evaporation technique and solvent displacement or nanoprecipitation method for nanoparticle preparation (Mendoza-Muñoz et al., 2012). It is a modification of the emulsion diffusion technique. In this method, drug and polymer are dissolved in a water-miscible organic solvent like acetone, followed by emulsification into an aqueous gel containing salting-out agent (magnesium chloride, calcium chloride, magnesium acetate, and sucrose) and a colloidal stabilizer. Colloidal stabilizer (polyvinyl pyrrolidone) is added in order to achieve stability for the dispersion phase of the emulsion. A large amount of aqueous medium is added to the emulsion $(\mathrm{o} / \mathrm{w})$ so that the diffusion of the solvent into the aqueous phase occurs and nanoparticles are formed. Cross-flow filtration is performed in order to remove the solvent and salting-out agent as they can affect the drug encapsulation efficiency. Advantages of this method include high efficiency, scale-up, and its usefulness for thermolabile substances. Certain disadvantages of this method are its limited applicability to lipophilic drugs and requisite of extensive nanoparticle washing.

\section{Ionic gelation Technique}

Ionic gelation method was previously called as ioninduced gelation. This method involves crosslinking of an ionic polymer with a counterionic material, which forms nanoparticles. If the polymer is positively charged, then the counterionic material is negatively charged in order to form cross-links. This crosslinking is due to electrostatic interactions between the polymer and counterionic material. It is followed by ionic gelation due to ionic interactions, which involves the transition of the material from a liquid into gel form at room temperature. In this method, the cluster is formed in the pre-gel phase by reaction of the polymer with a gelling agent. The prepared cluster is then stabilized by complex formation using polyelectrolyte. An example of this process is the formation of pre-gel phase using alginate with calcium which is then stabilized by different polycations, such as chitosan (De and Robinson, 2003; Douglas and Tabrizian, 2005; Sarmento et al., 2007) and polylysine (Rajaonarivony et al., 1993). Disadvantages of this method include improper surface morphology, fragile particulate system, and high poly dispersibility index (Kunjachan and Jose, 2010; Patil and Chavanke, 2012).

\section{Sonication method}

In this method, nanoparticles are prepared by simply dissolving polymer and drug in an organic solvent. It is then allowed for sonication under appropriate conditions, followed by removal of the solvent by filtration and repeated washings to get drug-loaded polymeric nanoparticles (Shi et al., 2012). Sonication method is preferred for the dispersion of noninert and non-functionalized metal nanoparticles like $\mathrm{Cu}, \mathrm{Mn}$, and Al. Sonication increases the release of metal from metal nanoparticles which can be further accelerated with the addition of solubilizing agents like Bovine serum albumin. Depending upon sonication time, particle agglomeration, metal dissolution, and zeta potential also change to different extents (Pradhan et al., 2016).

\section{Preparation of lipid nanoparticles}

\section{High-pressure homogenization}

For the preparation of solid lipid nanoparticles of drugs, high-pressure homogenization is the major technique employed (Corrias and Lai, 2011). Main advantages of this technique include improved stability of the drug, enhanced drug loading, no use of organic solvents, and large-scale production (Ekambaram et al., 2012). It can be performed in two ways, i.e., hot homogenization and cold homogenization. A schematic representation of a hot and cold high-pressure homogenization technique for the preparation of lipid nanocarriers is shown in Figure 2. Hot homogenization is performed for lipophilic drugs and the process is operated at a temperature above the melting point of lipid. Lipid is melted and the drug is added to this, then this drug-loaded lipid is mixed with aqueous phase using a high shear mixer. Quality of pre-emulsion determines the final form of nanoparticles. Lipid nanoparticles are formed upon congealing the nanoemulsion at room temperature. Limitations and challenges of this method include its suitability for the thermostable drug, infiltration of the drug into the aqueous phase, and complications of the crystallization process (Mehnert and Mäder, 2001) (Parhi and Suresh, 2012). Also, during homogenization, drug distribution and loss may occur into the aqueous medium. This method produces particles of low size and narrow particle size distribution. To solve the problems associated with hot homogenization, cold homogenization method has been developed (Naseri et al., 2015). Cold homogenization is a type of high-pressure milling of suspension, in which lipid microparticles are prepared initially by melting lipid with drug and allowed to solidify quickly using liquid nitrogen or dry ice. The nanoparticles are obtained by homogenization of prepared microparticles below room temperature using high-speed stirring in cold aqueous surfactant. This method yields large sized particles with broad size homogenization (Parhi and Suresh, 2012). 


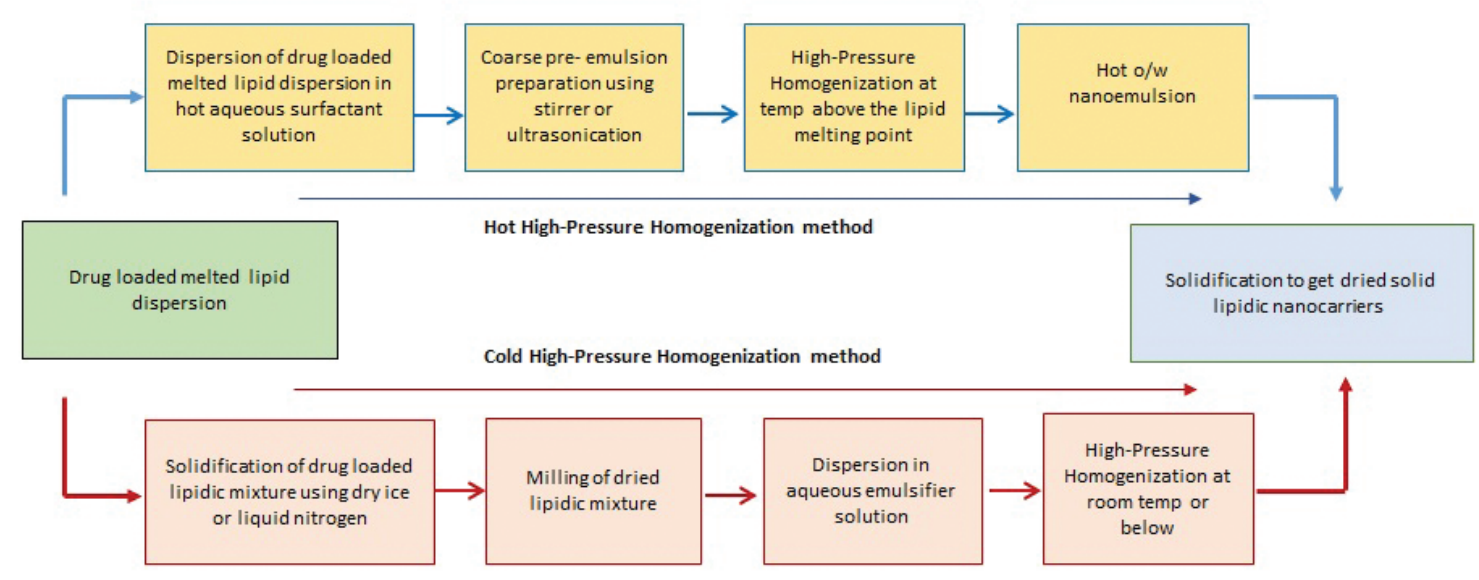

Figure 2. Hot and cold high-pressure homogenization technique for the preparation of lipid nanocarriers.

\section{Solvent emulsification evaporation}

In this method, nanoparticles are prepared by dissolving lipid and drug in a volatile organic solvent. Previously, dichloromethane and chloroform were used as solvents, but recently, ethyl acetate is widely used due to its better toxicological profile. The mixture is emulsified in an aqueous solvent containing a stabilizer [polyvinyl alcohol, poloxamer] (Ahlin Grabnar and Kristl, 2011). Sonication or high-energy homogenization is performed for the formation of emulsion $(\mathrm{O} / \mathrm{W})$ with smaller droplet size. The organic solvent is then removed either by stirring or under reduced pressure or by evaporation. This leads to the formation of nanoparticles by lipid precipitation. The nanoparticles are collected by using ultracentrifugation and by washing with distilled water. Experimental parameters, such as processing temperature, method for solvent evaporation, the volume of the aqueous phase, amount of surfactants, and molecular weight of polymer influence the physicochemical properties of prepared nanoparticles (Crucho and Barros, 2017). The concentration of lipid, surfactant, and co-surfactant in organic phase determines the particle size of prepared nanoparticles. With increasing lipid concentration, particle size increases and with decreasing concentration of polymer, particle size decreases. This method is suitable for thermolabile drugs as it is devoid of thermal stress. This method is limited to lipophilic drugs only and has some scale-up problems (Pinto Reis et al., 2006). The use of this method is limited due to time consumption and particle coalescence during the solvent evaporation (Fornaguera et al., 2015).

\section{Emulsification and solvent displacement method}

It is a modified method of solvent emulsification evaporation. Here, the lipid and drug are solubilized in a partially water-miscible organic solvent and then it is saturated with water to get a thermodynamic equilibrium between both the liquids. The solvent in the mixture gets diffused into the water as it is partially miscible with water and, as a result, lipid nanoparticles precipitate out from the disperse phase. This method can produce nanoparticles below $100 \mathrm{~nm}$ with low polydispersity index. The solvent can be removed from the system either by evaporation or filtration. Use of surfactants will alter the particle size. Non-ionic surfactants yield large particle size compared to ionic surfactants. Use of surfactants in a combination will give a synergistic effect and produce a better particle size. By adding oil like miglyol in an organic phase, nanocapsules can be obtained in place of nanospheres. The size of prepared nanocapsule is influenced by the concentration of oil, type of surfactant, and also the volume of solvent (Moinard-Chécot et al., 2008). This method yields high encapsulation efficiencies, better reproducibility, no need for homogenization, ease of scale-up, and narrow size distribution. Properties of prepared nanoparticles are influenced by process parameters including polymer and surfactant nature and concentration, type of solvent, agitation speed and time, type of stirrer, the temperature of dilution water, and viscosity of external phase (Bhatia, 2016; Colombo et al., 2001; Kwon et al., 2001) Disadvantages of this method include the elimination of high volumes of water from suspension and chances of leakage of the water-soluble drug during emulsification into aqueous external phase.

\section{Challenges in Nanodrug Delivery System}

Apart from the numerous advantages, there are certain challenges and limitations for nanotechnology, some of them are discussed as follows: (Desai, 2012; Jindal et al., 2017; Wei et al., 2012).

1. There are no regulatory standards for examination or characterization of nanoparticle medicines.

2. Problems in scale-up production of nanoparticles and lack of reproducibility in size and size distribution of nanoparticle.

3. Optimization of surface properties for targeted delivery and minimum non-specific adsorption.

4. Need for careful design and engineering for maintaining nonspecific cytotoxicity at a low level.

5. At the manufacturing scale, the process becomes expensive and there is a compromise in the yield and morphology of prepared nanoparticles.

Most of these challenges arise during the scale-up process from laboratory scale to manufacturing scale. Some of the effects occurring due to alteration in size, size distribution, and surface properties are discussed below. 
Particle size and size distribution are the most important characteristics of nanoparticle medicine as they significantly influence the pharmacokinetic properties and safety of the formulation. A rapid renal clearance occurs if the particle size is smaller than 20-30 $\mathrm{nm}$, whereas uptake by reticuloendothelial cells, liver, bone marrow, and spleen increases if the particle size is greater than or equal to $200 \mathrm{~nm}$.

Nanoparticle surface properties will significantly influence the behavior and interaction of nanoparticles with proteins and cells after entering into the body. Surface properties, such as charge, hydrophobicity, and functional groups, are associated with stability and opsonization process after entering into blood circulation. In the blood, these nanoparticles bind with various components, such as albumin, fibrinogen, IgG, and apolipoproteins through a process called opsonization which leads to clearance of nanoparticles by macrophages due to activation of the alternate pathway. Particles with the hydrophobic surface are directly taken up by macrophages without opsonization process.

Some of the desired properties of nanoparticles are lost during the process of scale-up. For example, during scale-up of a process using the emulsion method, it was noted that with the increase in the impeller speed and agitation time, there is a decrease in the particle size without any change in entrapment efficiency.

\section{Self-assembled nanoparticles drug delivery system}

In order to avoid these complications arising during scale-up, there is a novel approach of drug delivery that is "in situ" or "self-assembled" nanoparticles drug delivery system. This is the process in which nanoparticles are formed after administration of formulation into the body. As this concept is at its very juvenile stage, a limited formulation approaches have been investigated where different types of polymers, surfactants, or novel process are employed in order to prepare a pre-concentrate of drug formulation which on entering into an aqueous medium (GI fluid, blood) forms the nanoparticles. The in situ nanoformulations can be the futuristic approach in nanocarriers to overcome the problems associated with the scale-up process and also minimize the cost of production. These self-assembled nanoformulations have been studied for delivery of antiviral drugs, anticancer drugs, and antihyperlipidemic.

Various approaches have been attempted in order to deliver the drug through in situ or self-assembled nanoparticles drug delivery system. Jindal et al. (2017) prepared in situ hybrid nano drug delivery system (IHN-DDS) of nevirapine (NVP) for simultaneous targeting to multiple viral reservoirs. Initially, preconcentrate of drug, lipid, and surfactant was prepared. They have used poloxamer 188 at different concentrations as a surfactant, either stearic acid or polyglyceryl-6-distearate as lipid, and N,Ndimethylacetamide as a solvent. Prepared preconcentrate was diluted with distilled water in order to obtain IHN-DDS. The mean particle size was found to be $<200 \mathrm{~nm}$ in size with zeta potential of $-26.8 \pm 2.1 \mathrm{mV}$, which indicated higher colloidal stability of insitu nano preparation. It was found that changes in poloxamer concentration from $0.1 \% \mathrm{w} / \mathrm{v}$ to $1 \% \mathrm{w} / \mathrm{v}$ influenced the particle size and \% entrapment efficiency (EE). In vitro release studies stated that $35 \%$ of the drug showed burst release from HN-DDS in the first 1 hour, which may be due to surface entrapment or free drug. Later it was observed that the release followed slow and sustain form up to 24 hours. Stability studies for 6 months showed good stability with no significant change in particle size distribution. In vivo biodistribution studies were performed in Sprague-Dawley rats, which demonstrated 6 folds higher plasma concentration compared to free NVP solution at 1 hour. Increased drug accumulation by $6.1,5.8$, and 3.7 folds was observed in liver, spleen, and brain, respectively, at 1 hour. In vitro and in vivo results demonstrated that design in situ nanopreparation can provide desired physicochemical dispersion properties after administration and can provide selective targeting to the major organ with appropriate modifications.

Lin et al. (2011) prepared and characterized the in situ formation of fenofibrate nanocrystals using a self-micro emulsifying drug delivery system (SMEDDS). The formulation was composed of Myritol $^{\circledR}$, surfactant mixture of D- $\alpha$-Tocopheryl polyethylene glycol 1000 succinate (TPGS), and either tween 20 or tween 80 at various proportions of oil and surfactant mixture. Here, they employed the SMEDDS method in order to prepare a preconcentrate of drug, surfactant, oil, and cosolvents. The formed preconcentrate upon entering into water or $\mathrm{pH} 1.2$ simulated gastric acid will convert into $\mathrm{O} / \mathrm{W}$ microemulsion with nanosized droplet range. The physicochemical characterization shows that the prepared formulations were in the nanosize range, i.e., 200 $\mathrm{nm}$. Formulations containing tween 80 series showed faster release rate and complete release compared to tween 20 with an insignificant difference between them. They also compared designed nanoformulation with marketed formulation Tricor ${ }^{\circledR}$ for relative bioavailability. It was found that relative bioavailability was enhanced by 1.14-1.22 folds.

Kapse et al. (2012) prepared tamoxifen citrate (TMX) pre-concentrate using self nanoprecipitation method for enhancing bioavailability. They have prepared a pre-concentrate of TMX, kollidon SR as polymer and binary surfactant mixture of aerosol OT (AOT) and tween 80 or mirj-52 or Pluronic-F68 (PF-68). The pre-concentrate upon dilution with aqueous media converted into polymeric nanoparticles of TMX. Results showed that particle size and entrapment efficiency were highly influenced by the type and concentration of the surfactant used. Non-ionic surfactant yielded larger particle size of $>1 \mu \mathrm{m}$ with low EE of $<30 \%$, whereas in case of anionic surfactant, AOT produced $\mathrm{EE}$ of $>80 \%$ due to ionic complexation with TMX. Binary surfactant mixture produced better results compared to individual components. Due to the interaction of binary surfactant and a simultaneous decrease in surface tension result in nanosized particles. At $1 \%$ and $5 \% \mathrm{v} / \mathrm{v}$ of tween 80 , particle size was found to be $238 \pm 2.1 \mathrm{~nm}$ and $108 \pm 2.1 \mathrm{~nm}$ and with Mirj-52, 208.7 $\pm 2.5 \mathrm{~nm}$ and $116.1 \pm 3.2 \mathrm{~nm}$, respectively. Higher $\mathrm{EE}$ of $>80 \%$ and low particle size was obtained using tween 80 $(1 \% \mathrm{v} / \mathrm{v})$ and AOT $(1.5 \% \mathrm{v} / \mathrm{v})$ combination. Differential scanning calorimetry and X-ray powder diffraction results confirmed the conversion of a crystalline form of TMX into amorphous form in nanoformulation. TEM image showed the spherical shape and nanosize of the obtained TMX nanoparticles. Bioavailability 
studies on rat showed an increase in relative bioavailability of TMX nanoparticles by $165.61 \%$ compared to free TMX, which may be due to the direct intake of nanoparticles by lymphatic circulation.

\section{Preparation of self-assembled nanocarriers}

\section{Building blocks}

There are specific polymeric materials available for building up self-assembled nanocarrier, which can be natural or synthetic (Irby et al., 2017; Kohli et al., 2014; LaManna et al., 2012). Many synthetic polymeric nanoformulations have been studied because of their flexibility, countless availability, and ability to tailor with different sizes and morphology and modification with functionality (Mora-Huertas et al., 2010). Water dispersive polymers with hydrophilic side chain and hydrophobic backbone as well as amphiphilic copolymers are widely used in the preparation of self-assembled nanocarriers.

Recently, the application of natural, synthetic, and recombinant proteins have increased in the drug delivery system due to their many advantages like biocompatible, biodegradable, and high degree of self-assembly. Proteins as building block provide the unique option of the delivery system with a properly defined internal and external surface, undeviating morphology, and wide options of shapes and sizes ranging from 18 to 500 $\mathrm{nm}$. Natural polysaccharides have also been emerging as a natural polymer for nanocarriers. Hybrid material by using two or three different types of material increases the choice of building block which can be used for maintaining the properties of nanoformulation.

\section{Encapsulation of drug}

There are different methods for encapsulation of drug depending upon the nature of the drug and the type of nano preparation. Carrier molecule can be used to find which drug can be covalently attached and assembled inside the nanocarrier like polymer-drug conjugates. Proteins and gene are delicate in nature; therefore, they are capsulated inside the nanocarrier to maintain their stability and prevent them from metabolism. For attachment of proteins to delivery molecules, bioconjugate reactions are highly advisable to retain the activity of the protein as these reactions are very specific and there are fewer chances of structural changes in proteins (Beck et al., 2017; Sivaram et al., 2018). Coulombic interactions can be used for gene therapy and gene delivery as this provides a steady force which prevents undesired leaking. A hydrogen bond is another option for encapsulation. Although hydrogen bond is less advisable in the aqueous solution, here the drug is out of the reach of water; therefore, hydrogen bonded drug can be stably encapsulated inside the carrier.

\section{Drug Release from Self-Assembled Nanocarriers}

Like building up, drug release is also a very important part in self-assembled nanomedicines. Depending upon the interaction of nanocarrier with the surrounding environment, releasing modes can be categorized into two kinds; nonstimuliresponsive release and stimuli-sensitive release.

\section{Non-stimuli-responsive release}

In this case, the carrier would sharply break and blowout all the drugs at once. In sustained release nanoformulation, it will take more time because the time taken for detachment and dispersion of drug and then continuous erosion of carrier is more. These carriers may be biodegradable or non-biodegradable. Nanoparticles in which non-biodegradable carrier like polystyrene or poly(methyl methacrylate) is being used, are fabricated as porous structures on which drug first attaches, then detaches and, finally, diffuses out from it. Osmotic pressure plays an important role in drug release as it acts as a driving force for the drug (Keraliya et al., 2012). In biodegradable nanocarriers, hydrolyzable bonds are introduced to release the drug from the carrier. The main disadvantage of nonstimuli-responsive release is that the drug may release before reaching to the target site and this system is uncontrollable.

\section{Stimuli-responsive release}

The controllable release of the drug can be achieved by incorporating responsive groups in nanoparticles which breaks in the presence of certain stimuli (Jin et al., 2018). On breakage, whole structure disrupts and drug releases out. Based on the stimuli exercised, they can be divided as internal stimuli and external stimuli. When there is variation in the target site such as a change in $\mathrm{pH}$, different expression of enzymes, other molecules in tissue, and abnormal redox environment, then internal stimuli is originated.

pH stimuli

Due to the Warburg effect, tumor cell proliferates at a high rate and there is a deficiency of nutrients which results in accelerated glycolysis and lactic acid accumulation, leading to lower environmental pH (Estrella et al., 2013). This difference in $\mathrm{pH}$ acts as an internal stimulus which activates the drug release. $\mathrm{pH}$ stimuli cause hydrolysis due to which either bond breaks and structure degenerates or there can be a change in molecular interaction because of protonation, which, in turn, causes breakage of the assembly. Different kinds of moieties which are cleaved in acidic environments, such as hydrazine, acetal, amine, orthoester, boronic acid ester, and vinyl ether, have been introduced and studied. $\mathrm{pH}$ difference between intracellular endosomes/lysosomes and extracellular matrix is more than that of the extracellular matrix of normal and cancer cells, which is more advantageous for drug release (Yameen et al., 2014). Nanocarriers are transported into lysosomes, where the carrier is lysed and the drug gets released.

\section{Redoxstimulus}

Glutathione (GSH) serves as a general reductant for cells and also plays other functions including bioactivity maintenance, redox state maintenance, and xenobiotics detoxification. GSH concentration is a thousand times more inside the cell than that of the extracellular matrix. In tumor cells, the concentration of GSH increases additionally. Nanoparticulate systems containing carriers with disulfide and diselenide bond can be used to deliver the drug in these tumors because these bond can be broken by GSH (Ortega et al., 2011). 
Reactive oxygen species (ROS) are oxygen-containing highly reactive chemical species like superoxide (O2-), hydroxyl radical $(\mathrm{HO} \bullet)$, nitric oxide $(\mathrm{NO} \bullet)$, peroxyl radicals $(\mathrm{ROO} \bullet)$, hydrogen peroxide $\left(\mathrm{H}_{2} \mathrm{O}_{2}\right)$, ozone/trioxygen $\left(\mathrm{O}_{3}\right)$, and other high-reacting substances. ROS are vital for cellular activity because they are involved in all processes for cell differentiation, propagation, and transferring of intracellular vesicles. In cancer cell, ROS concentration increases which lead to an alteration in the redox state of the tumor cell. Carriers containing selenide can disrupt tumor cells due to the higher concentration of ROS which oxidizes selenide to selenoxide which increases hydrophilicity and this causes the drug release. Carriers with oxidative cleavable moieties, such as thioketals, boronic esters, and polyprolines release drugs easily in the presence of ROS (Zeng et al., 2016).

\section{Temperature stimuli}

Targeted delivery of nanoparticle is mainly required for tumor cells where there is abnormal temperature due to many reasons such as accelerated metabolic reactions, accelerated cell proliferation, and leukocyte infiltration (Hurwitz and Stauffer, 2014). In some experiment, it was found that the release of the encapsulated drug was more when it was heated up to phasetransition temperature $\left(T_{\mathrm{m}}\right)$. With the change in temperature, physical state and mobility of lipid changes like below $T_{\mathrm{m}}$ lipid molecules remain in gel state as these molecules are well-ordered and get condensed and remain immobile while at temperature reaching to $T_{\mathrm{m}}$, head group of molecules becomes mobile and its state changes from gel to the liquid crystalline phase. At exact $T_{\mathrm{m}}$ temperature, both liquid and solid lipid phase exist and create interphase through which drug leaks causing an increase in permeation.

Introduction of temperature-sensitive polymer like poly( $N$-isopropylacrylamide) (p-NIPAM), poly(vinyl ethers), and their derivatives in nanocarrier is another way of producing temperature responsive delivery system as they can change the conformations according to the change in temperature. Stability of polymer depends on their low critical solution temperature (LCST). Below this temperature, the polymer is stable but as the temperature increases above LCST, polymer chain gets condensed and results in the destruction of the nanocarrier. LCST of any polymer can be adjusted according to the requirement of targetspecific drug release by copolymerization with other monomers having different hydrophilicity and hydrophobicity (Zhao et al., 2015).

\section{Enzyme and other biomolecules stimuli}

When carrier contains linker which can be cleaved by enzymes, they behave as a substrate for enzymes and release drugs after enzymolysis. There are many enzymes, for example, protease, esterase, phospholipase, and many more which break covalent bonds of biomacromolecules like phospholipids and act as a decomposer. Along with enzymes, some small molecules such as Adenosine- $5^{\prime}$-triphosphate (ATP) can also act as triggers. ATP is an essential biomolecule present in high concentration inside the cell than that of the extracellular environment. This difference in concentration provides an opportunity to develop ATP-responsive carriers (Mo et al., 2014).

\section{Light stimuli}

It is a type of external stimulus which can trigger accurate drug release at the site of action. Upon light irradiation, structural transformation occurs in nanoparticles and it gets collapsed. At a particular wavelength of light, the bond gets cleaved and there occur configurational and electrostatic changes, which, in turn, disrupt the nanocarrier moiety. Most of the triggered transitions are based on UV to visible light with a short wavelength. However, the major problem in light triggered drug release is shallow penetration in tissues. Near-infrared (NIR) provides an advantage over UV light as it can go deeper into the tissue. Other than NIR, bioluminescence is another option to solve the problem of penetration by UV light, and it also avoids the need of an external source for radiation as bioluminescence of luminol can be absorbed by molecules. To overcome the problem of poor penetration, longpersistent luminescence material can also be used (Abdurahman et al., 2016; Fan et al., 2017; Wang et al., 2017).

\section{Other stimuli}

Other than above-mentioned stimulus, magnetic field response, electric field response, and ultrasound stimuli are other external mechanisms (Manouras and Vamvakaki, 2017) to trigger drug release. Combination of both internal and external stimuli provides several approaches for responsive drug release.

\section{Challenges of Self-Assembled Nanocarriers}

Despite having eminent properties, such as selective targeting, reducing the side effects of conventional therapy, enhancing the pharmacokinetic profile of the drug, and improved efficiency of drug delivery, there are some limitations of selfassembled nanocarriers which restrict its industrialization. Many nanocarriers are found to be toxic in clinical observations but this drawback can be solved by adjusting the parameters of nanoparticles, including shape, size, composition, and surface modification (Chen et al., 2016). Nanocarriers are used to enhance the permeability of drugs but this can result in the accumulation of the drug in tumor tissues. This prolongs accumulation is decreased in delivery efficacy of the drug to tumor site along with a reduction in the improvement of the overall survival of patients (Nakamura et al., 2016).

When these nanocarriers are delivered into the biological system, it interacts with biomolecules in a nonspecific manner which makes the delivery process unpredictable (Mahmoudi et al., 2011; Monopoli et al., 2012). In a biological environment, nanocarrier is covered with several biomolecules after reaching there, which make uncertain alterations in its size, stability, and surface properties, which, in turn, changes the properties of nanoformulation related to its distribution, cellular uptake, drug effect, and toxicity.

Additionally, there are major challenges in scale-up and reproducibility. Extensive research studies are under progression for different categories of drugs with feasible methods to improve the existing problems of these drugs and to provide improved therapeutic efficacy (Table 1). There is great hope with advanced and improved technology and composition for nanocarriers preparation which can provide selective delivery and minimize the adverse reactions with an affordable cost of therapy. Additionally, regulatory agencies are also working on quality and safety aspects of nanocarriers-based delivery systems. 
Table 1. Nanoformulations prepared with different techniques.

\begin{tabular}{|c|c|c|c|}
\hline Method of preparation & Type of nanoformulation & Drug & References \\
\hline \multirow{7}{*}{ Milling Method } & Nanocrystal & $\begin{array}{l}\text { Niclosamide (Anthelmintic } \\
\text { drug) }\end{array}$ & (Ye et al., 2015) \\
\hline & Amorphous ternary cyclodextrin nanocomposites of telmisartan & Telmisartan & (Sangwai and Vavia, 2013) \\
\hline & Nanocrystals embedded in microparticles & Indomethacin & (Laaksonen et al., 2011) \\
\hline & Ophthalmic Nanosuspension & Miconazole (Antifungal) & (Cerdeira et al., 2010) \\
\hline & Polymeric microspheres and drug-polymer composites & Ketoprofen & (Kluge and Mazzotti, 2012) \\
\hline & Lipid Nanoparticle & Quercetin (Topical) & (Scalia et al., 2013) \\
\hline & Intravenous Lipid Emulsion & Tanshinone IIA & (Chu et al., 2012) \\
\hline \multirow{8}{*}{ Solvent Emulsification Evaporation } & Nanostructured lipid carrier gel & Minoxidil & (Uprit et al., 2013) \\
\hline & Nanoliposome & Curcumin & (Hong et al., 2008) \\
\hline & Nanostructured lipid carrier & Amoitone B & (Luan et al., 2014) \\
\hline & Protein-polymer conjugate & Tanshinone IIA & (Pelegri-O'Day and Maynard, 2016) \\
\hline & Nanostructured lipid carrier & Ketoprofen & (Müller et al., 2007) \\
\hline & Lipid Nanoparticle & Lercanidipine $\mathrm{HCl}$ & (Ranpise et al., 2014) \\
\hline & Nanoparticle & Bovine albumin & (Häuser et al., 2015) \\
\hline & Lipid polymer nanoparticle & Amoxicillin & (Cai et al., 2015) \\
\hline \multirow{4}{*}{ Nanoprecipitation } & Nanoparticle & Pioglitazone Hydrochloride & (Canchi et al., 2018) \\
\hline & Self-assembled lipid-polymer hybrid nanoparticles & Mitomycin C & (Garg et al., 2015) \\
\hline & Lipid polymer nanoparticle & Indocyanine green & (Zhao et al., 2014) \\
\hline & Nanoparticles loaded with small interference RNA & DNase I & (Cui et al., 2014) \\
\hline \multirow{7}{*}{ Solvent Emulsification Diffusion } & Pentapeptide grafted nanostructured lipid carriers & Dexamethasone & (Zhao et al., 2013) \\
\hline & Nanostructured lipid carrier & Isoliquiritigenin & (Zhang et al., 2013b) \\
\hline & Protein-free nanostructured lipid carrier & Lovastatin & (Gu et al., 2011) \\
\hline & Nanostructured lipid carriers & Gentiopicroside & (Zhang et al., 2013a) \\
\hline & Nanostructured Lipid Carriers & Paclitaxel & (Emami et al., 2012) \\
\hline & Nanostructured lipid carriers & Celastrol & (Zhou et al., 2012) \\
\hline & Nanostructured lipid carriers & Voriconazole & (Waghule et al., 2019) \\
\hline \multirow{11}{*}{ High-Pressure Homogenization } & Solid lipid nanoparticles and nanostructured lipid carriers & Bromidine base & (El-Salamouni et al., 2015) \\
\hline & Nanostructured lipid carrier & Lornoxicame & (Yang et al., 2013) \\
\hline & Nanostructured lipid carriers & Quercetin & (Beloqui et al., 2014) \\
\hline & Hybrid Nanoparticle & UvinulT 150 & (Tolbert et al., 2016) \\
\hline & Nanostructured lipid carriers & Thymoquinone & (Abdelwahab et al., 2013) \\
\hline & Nanostructured Lipid Carriers & Docetaxel & (Choi et al., 2016) \\
\hline & Nanostructured lipid carriers & $\beta$-Elemene & (Shi et al., 2013) \\
\hline & Nanostructured lipid carriers & Fenofibrate & (Tran et al., 2014) \\
\hline & Lipid-polymer hybrid nanoparticles & Dextran & (Ramasamy et al., 2014) \\
\hline & Lipid-polymer hybrid nanoparticles & Vancomycin & (Seedat et al., 2016) \\
\hline & Hydroxyapatite nanoparticles & Methylprednisolone & (Jafari et al., 2016) \\
\hline \multirow{4}{*}{ Extrusion } & Nanoparticle & Anacetrapib & (Harmon et al., 2016) \\
\hline & Self-emulsifiable nanocomposites & Cupric-sulfate & (Koo et al., 2018) \\
\hline & Solid dispersion & Naproxen & (Haser et al., 2017) \\
\hline & Nanocomposites & Zinc sulfate monohydrate & (Lee et al., 2017) \\
\hline \multirow{5}{*}{ Super Critical Fluid } & Nanoparticles & Cefquinome & (Kefeng et al., 2015) \\
\hline & Solid lipid nanoparticles & Indomethacin & (Chattopadhya et al., 2007) \\
\hline & Solid lipid nanoparticles & Ibuprofen & (Akbari et al., 2015) \\
\hline & Poly(3-hydroxybutyrate-co-3-hydroxyhexanoate) nanoparticles & Bortezomib & (Demirdöğen et al., 2018) \\
\hline & Nanosuspension & Stearic acid & (Campardelli et al., 2013) \\
\hline
\end{tabular}




\begin{tabular}{|c|c|c|c|}
\hline Method of preparation & Type of nanoformulation & Drug & References \\
\hline \multirow{3}{*}{ Salting Out } & Polylactic acid-Carboxy Methyl Cellulose nanocarriers & Cisplatin & (Hari Balakrishanan and Rajan, 2016) \\
\hline & Magnetic Silk Fibroin Nanoparticles & Doxorubicin & (Tian et al., 2014) \\
\hline & $\gamma-\mathrm{Al}_{2} \mathrm{O}_{3}$ supported $\mathrm{CeO}_{2}$ shell Nanosphere & $\mathrm{Pd}$ & (Wang et al., 2015) \\
\hline \multirow[b]{2}{*}{ Ion Gelation technique } & Chitosan nanoparticles & Salicylic acid & (Dong et al., 2013) \\
\hline & Nanoparticles of Chitosan derivatives & $\begin{array}{l}\text { Taxanes (Paclitaxel and } \\
\text { docetaxel) }\end{array}$ & (Skorik et al., 2017) \\
\hline \multirow{3}{*}{ Sonication } & Solid Lipid Nanoparticle & Curcumin & (Ramalingam et al., 2016) \\
\hline & Nanostructure & Titanium Dioxide & (Pinjari et al., 2015) \\
\hline & Nanoparticle & Lignin & (Gilca et al., 2015) \\
\hline
\end{tabular}

\section{CONCLUSION}

Due to the inability of conventional formulation in targeting the desired site and associated formulation problems, nanoformulations, such as liposomes, dendrimers, SLNs, NLCs, microemulsions, nanoemulsions, quantum dots, and so on have been developed. Nanoformulations proved advantages like enhanced bioavailability, site-specific delivery, improved stability, and reduced side effects over traditional form of delivery. However, due to certain limitations of nanoformulations such as scale-up issues, stability concern, batch reproducibility, cytotoxicity at low levels, and the problem with surface characterization, in situ or self-assembled nanocarriers system became an attractive strategy for industrial acceptance. In situ nanoformulation approach has successfully overcome the drawbacks of traditional nanoformulations and also showed advantages over complex nano composition methods which produce different sizes of nanoparticles. As these nanomedicines are in their infancy stage, there are many challenges which are limiting its large-scale production. It is expected that as the number of research studies in this area increases, the formulations from laboratory scale will transcend to market in the near future for therapeutics and clinical purpose. By exploring more about it, the present challenges can be resolved and then more advanced medication can come in the market targeting better efficacy and patient acceptability.

\section{FUNDING}

The present work is not funded by any agency.

\section{CONFLICT OF INTEREST}

Authors declare that there are no conflict of Interest.

\section{REFERENCES}

Abdelwahab SI, Taha, Sheikh, How, El-Sunousi, Abdullah, Eid, Umar Yagoub. Thymoquinone-loaded nanostructured lipid carriers: preparation, gastroprotection, in vitro toxicity, and pharmacokinetic properties after extravascular administration. Int J Nanomedicine, 2013; 8:2163-72; doi:10.2147/IJN.S44108

Abdurahman R, Yang CX, Yan XP. Conjugation of a photosensitizer to near infrared light renewable persistent luminescence nanoparticles for photodynamic therapy. Chem Commun (Camb), 2016; 52:13303-6; doi:10.1039/c6cc07616e

Ahlin Grabnar P, Kristl J. The manufacturing techniques of drugloaded polymeric nanoparticles from preformed polymers. J Microencapsul, 2011; 28:323-35; doi:10.3109/02652048.2011.569763

Akbari Z, Amanlou M, Karimi-Sabet J, Golestani A, Shariaty Niassar M. Production of ibuprofen-loaded solid lipid nanoparticles using rapid expansion of supercritical solution. J Nano Res, 2015; 31:15-29; doi:10.4028/www.scientific.net/JNanoR.31.15

Beck A, Goetsch L, Dumontet C, Corvaïa N. Strategies and challenges for the next generation of antibody-drug conjugates. Nat Rev Drug Discov, 2017; 16:315-37; doi:10.1038/nrd.2016.268

Beloqui A, Solinís MÁ, Rieux A des, Préat V, Rodríguez-Gascón A. Dextran-protamine coated nanostructured lipid carriers as mucuspenetrating nanoparticles for lipophilic drugs. Int J Pharm, 2014; 468: 105-11; doi:10.1016/j.ijpharm.2014.04.027

Bhatia S. Nanoparticles types, classification, characterization, fabrication methods and drug delivery applications. In: Natural polymer drug delivery systems, Springer International Publishing, Cham, Switzerland, pp 33-93, 2016; doi:10.1007/978-3-319-41129-3 2

Byrappa K, Ohara S, Adschiri T. Nanoparticles synthesis using supercritical fluid technology — towards biomedical applications. Adv Drug Deliv Rev, 2008; 60:299-327; doi:10.1016/j.addr.2007.09.001

Cai J, Huang H, Song W, Hu H, Chen J, Zhang L Li P, Wu R, Wu C. Preparation and evaluation of lipid polymer nanoparticles for eradicating $\mathrm{H}$. pylori biofilm and impairing antibacterial resistance in vitro. Int J Pharm, 2015; 495:728-37; doi:10.1016/j.ijpharm.2015.09.055

Campardelli R, Cherain M, Perfetti C, Iorio C, Scognamiglio M, Reverchon E, Della Porta G. Lipid nanoparticles production by supercritical fluid assisted emulsion-diffusion. J Supercrit Fluids, 2013; 82:34-40; doi:10.1016/j.supflu.2013.05.020

Canchi A, Khosa A, Singhvi G, Banerjee S, Dubey SK. Design and characterization of polymeric nanoparticles of pioglitazone hydrochloride and study the effect of formulation variables using QbD approach. Curr Nanomater, 2018; 2:162-8; doi:10.2174/24054615036661 80501115359

Cerdeira AM, Mazzotti M, Gander B. Miconazole nanosuspensions: influence of formulation variables on particle size reduction and physical stability. Int J Pharm, 2010; 396:210-8; doi:10.1016/j. ijpharm.2010.06.020

Chattopadhyay P, Shekunov B, Yim D, Cipolla D, Boyd B, Farr $\mathrm{S}$. Production of solid lipid nanoparticle suspensions using supercritical fluid extraction of emulsions (SFEE) for pulmonary delivery using the AERx system. Adv Drug Deliv Rev, 2007; 59:444-53; doi:10.1016/j. addr.2007.04.010

Chen G, Roy I, Yang C, Prasad PN. Nanochemistry and nanomedicine for nanoparticle-based diagnostics and therapy. Chem Rev, 2016; 116:2826-85; doi:10.1021/acs.chemrev.5b00148

Choi KO, Choe J, Suh S, Ko S. Positively charged nanostructured lipid carriers and their effect on the dissolution of poorly soluble drugs. Molecules, 2016; 21:672; doi:10.3390/molecules21050672

Chu T, Zhang Q, Li H, Ma W, Zhang N, Jin H, Mao S. Development of intravenous lipid emulsion of tanshinone IIA and evaluation of its anti-hepatoma activity in vitro. Int J Pharm, 2012; 424:7688; doi:10.1016/j.ijpharm.2011.12.049

Colombo AP, Briançon S, Lieto J, Fessi H. Project, design, and use of a pilot plant for nanocapsule production. Drug Dev Ind Pharm, 2001; 27:1063-72; doi:10.1081/DDC-100108369 
Corrias F, Lai F. New methods for lipid nanoparticles preparation. Recent Pat Drug Deliv Formul, 2011; 5: 201-13.

Couvreur P. Nanoparticles in drug delivery: past, present and future. Adv Drug Deliv Rev, 2013; 65:21-23; doi:10.1016/j. addr.2012.04.010

Crucho CIC, Barros MT. Polymeric nanoparticles: a study on the preparation variables and characterization methods. Mater Sci Eng C, 2017; 80:771-84; doi:10.1016/j.msec.2017.06.004

Cui X, Liu R, Liu Z, Shen X, Wang Q, Tan X. Cationic PolyL-Lysine-Fe2O3/SiO2 nanoparticles loaded with small interference RNA: application to silencing gene expression in primary rat neurons. J Nanosci Nanotechnol, 2014; 14:2810-5.

De S, Robinson D. Polymer relationships during preparation of chitosan-alginate and poly-1-lysine-alginate nanospheres. J Control Release, 2003; 89:101-12.

Demirdöğen RE, Emen FM, Ocakoglu K, Murugan P, Sudesh $\mathrm{K}$, Avşar G. Green nanotechnology for synthesis and characterization of poly(3-hydroxybutyrate- co -3-hydroxyhexanoate) nanoparticles for sustained bortezomib release using supercritical CO 2 assisted particle formation combined with electrodeposition. Int J Biol Macromol, 2018; 107:436-45; doi:10.1016/j.ijbiomac.2017.09.011

Desai N. Challenges in development of nanoparticle-based therapeutics. AAPS J, 2012; 14:282-95; doi:10.1208/s12248-012-9339-4

Dong Y, Ng WK, Shen S, Kim S, Tan RBH. Scalable ionic gelation synthesis of chitosan nanoparticles for drug delivery in static mixers. Carbohydr Polym, 2013; 94:940-5; doi:10.1016/j.carbpol.2013.02.013

Douglas KL, Tabrizian M. Effect of experimental parameters on the formation of alginate-chitosan nanoparticles and evaluation of their potential application as DNA carrier. J Biomater Sci Polym Ed, 2005; $16: 43-56$.

Dua K, Chellappan DK, Singhvi G, de Jesus Andreoli Pinto T, Gupta G, Hansbro PM. Targeting microRNAs using nanotechnology in pulmonary diseases. Panminerva Med, 2018a; 60:230-1; doi:10.23736/ S0031-0808.18.03459-6

Dua K, Malyla V, Singhvi G, Wadhwa R, Krishna RV, Shukla SD, Shastri MD, Chellappan DK, Maurya PK, Satija S, Mehta M, Gulati M, Hansbro N, Collet T, Awasthi R, Gupta G, Hsu A, Hansbro PM. Increasing complexity and interactions of oxidative stress in chronic respiratory diseases: an emerging need for novel drug delivery systems. Chem Biol Interact, 2019; 299:168-78; doi:10.1016/J.CBI.2018.12.009

Dua K, Rapalli VK, Shukla SD, Singhvi G, Shastri MD, Chellappan DK, Satija S, Mehta M, Gulati M, Pinto TDJA, Gupta G, Hansbro PM. Multi-drug resistant Mycobacterium tuberculosis \& oxidative stress complexity: Emerging need for novel drug delivery approaches. Biomed Pharmacother, 2018b; 107:1218-29; doi:10.1016/J.BIOPHA.2018.08.101

Ekambaram P, Abdul A, Sathali H, Priyanka K. Solid lipid nanoparticles: a review. Sci Revs Chem Commun, 2012; 2:80-102.

El-Salamouni NS, Farid RM, El-Kamel AH, El-Gamal SS Effect of sterilization on the physical stability of brimonidine-loaded solid lipid nanoparticles and nanostructured lipid carriers. Int J Pharm, 2015; 496:976-83; doi:10.1016/j.ijpharm.2015.10.043

Emami J, Rezazadeh M, Varshosaz J, Tabbakhian M, Aslani A. Formulation of LDL targeted nanostructured lipid carriers loaded with paclitaxel: a detailed study of preparation, freeze drying condition, and in vitro cytotoxicity. J Nanomater, 2012; 2012:1-10; doi:10.1155/2012/358782

Estrella V, Chen T, Lloyd M, Wojtkowiak J, Cornnell HH, Ibrahim-Hashim A, Bailey K, Balagurunathan Y, Rothberg JM, Sloane BF, Johnson J, Gatenby RA, Gillies RJ. Acidity generated by the tumor microenvironment drives local invasion. Cancer Res, 2013; 73:1524-35; doi:10.1158/0008-5472.CAN-12-2796

Fan W, Lu N, Xu C, Liu Y, Lin J, Wang S, Shen Z, Yang Z, Qu J, Wang T, Chen S, Huang P, Chen X. Enhanced afterglow performance of persistent luminescence implants for efficient repeatable photodynamic therapy. ACS Nano, 2017; 11:5864-72; doi:10.1021/acsnano.7b01505

Fattahi A, Karimi-Sabet J, Keshavarz A, Golzary A, RafieeTehrani M, Dorkoosh FA. Preparation and characterization of simvastatin nanoparticles using rapid expansion of supercritical solution (RESS) with trifluoromethane. J Supercrit Fluids, 2016; 107:469-78; doi:10.1016/j supflu.2015.05.013

Fornaguera C, Feiner-Gracia N, Calderó G, García-Celma MJ, Solans C. Galantamine-loaded PLGA nanoparticles, from nanoemulsion templating, as novel advanced drug delivery systems to treat neurodegenerative diseases. Nanoscale, 2015; 7:12076-84; doi:10.1039/ C5NR03474D

Garg NK, Singh B, Sharma G, Kushwah V, Tyagi RK, Jain S, Katare OP. Development and characterization of single step self-assembled lipid polymer hybrid nanoparticles for effective delivery of methotrexate. RSC Adv, 2015; 5:62989-99; doi:10.1039/C5RA12459J

Gilca IA, Popa VI, Crestini C. Obtaining lignin nanoparticles by sonication. Ultrason Sonochem, 2015; 23:369-75; doi:10.1016/j. ultsonch.2014.08.021

Girdhar V, Patil S, Banerjee S, Singhvi G. Nanocarriers for drug delivery: mini review. Curr Nanomedicine, 2018; 8:88-99; doi:10.2174/24 68187308666180501092519

Girotra P, Singh SK, Nagpal K. Supercritical fluid technology: a promising approach in pharmaceutical research. Pharm Dev Technol, 2013; 18:22-38; doi:10.3109/10837450.2012.726998

Gu X, Zhang W, Liu J, Shaw JP, Shen Y, Xu Y, Lu H, Wu Z. Preparation and characterization of a lovastatin-loaded protein-free nanostructured lipid carrier resembling high-density lipoprotein and evaluation of its targeting to foam cells. AAPS PharmSciTech, 2011; 12:1200-8; doi:10.1208/s12249-011-9668-0

Guo P, Hsu TM, Zhao Y, Martin CR, Zare RN. Preparing amorphous hydrophobic drug nanoparticles by nanoporous membrane extrusion. Nanomedicine, 2013; 8:333-41; doi:10.2217/nnm.12.119

Guo P, Huang J, Zhao Y, Martin CR, Zare RN, Moses MA Nanomaterial Preparation by Extrusion through Nanoporous Membranes. Small, 2018; 14:1703493; doi:10.1002/smll.201703493

Hari Balakrishanan M, Rajan M. Size-controlled synthesis of biodegradable nanocarriers for targeted and controlled cancer drug delivery using salting out cation. Bull Mater Sci, 2016; 39(1):69-77.

Harmon $\mathrm{P}$, Galipeau $\mathrm{K}, \mathrm{Xu} \mathrm{W}$, Brown $\mathrm{C}$, Wuelfing WP Mechanism of dissolution-induced nanoparticle formation from a copovidone-based amorphous solid dispersion. Mol Pharm, 2016; 13:146781; doi:10.1021/acs.molpharmaceut.5b00863

Haser A, Cao T, Lubach J, Listro T, Acquarulo L, Zhang F. Melt extrusion vs. spray drying: the effect of processing methods on crystalline content of naproxen-povidone formulations. Eur J Pharm Sci, 2017; 102:115-25; doi:10.1016/j.ejps.2017.02.038

Häuser M, Langer K, Schönhoff M. pH-Triggered release from surface-modified poly(lactic- $c o$-glycolic acid) nanoparticles. Beilstein J Nanotechnol, 2015; 6:2504-12; doi:10.3762/bjnano.6.260

Hong W, Chen DW, Zhao XL, Qiao MX, Hu HY. Preparation and study in vitro of long-circulating nanoliposomes of curcumin. Zhongguo Zhong Yao Za Zhi, 2008; 33:889-92.

Hurwitz M, Stauffer P. Hyperthermia, radiation and chemotherapy: the role of heat in multidisciplinary cancer care. Semin Oncol, 2014; 41:714-29; doi:10.1053/j.seminoncol.2014.09.014

Irby $\mathrm{D}, \mathrm{Du} \mathrm{C}$, Li F. Lipid-drug conjugate for enhancing drug delivery. Mol Pharm, 2017; 14:1325-38; doi:10.1021/acs. molpharmaceut.6b01027

Jafari S, Maleki-Dizaji N, Barar J, Barzegar-Jalali M, Rameshrad M, Adibkia K. Methylprednisolone acetate-loaded hydroxyapatite nanoparticles as a potential drug delivery system for treatment of rheumatoid arthritis: In vitro and in vivo evaluations. Eur J Pharm Sci, 2016; 91:22535; doi:10.1016/j.ejps.2016.05.014

Jin Q, Li H, Jin Z, Huang L, Wang F, Zhou Y, Liu Y, Jiang C, Oswald J, Wu J, Song X. TPGS modified nanoliposomes as an effective ocular delivery system to treat glaucoma. Int J Pharm. 2018; 553:21-8; doi:10.1016/j.ijpharm.2018.10.033

Jindal AB, Bachhav SS, Devarajan PV. In situ hybrid nano drug delivery system (IHN-DDS) of antiretroviral drug for simultaneous targeting to multiple viral reservoirs: an in vivo proof of concept. Int J Pharm, 2017; 521:196-203; doi:10.1016/j.ijpharm.2017.02.024 
Kapse SV, Gaikwad RV, Samad A, Devarajan PV. Self nanoprecipitating preconcentrate of tamoxifen citrate for enhanced bioavailability. Int $\mathrm{J}$ Pharm, 2012; 429:104-12; doi:10.1016/J. IJPHARM.2012.02.042

Keck C, Muller R. Drug nanocrystals of poorly soluble drugs produced by high pressure homogenisation. Eur J Pharm Biopharm, 2006; 62:3-16; doi:10.1016/j.ejpb.2005.05.009

Kefeng X, Weiqiang W, Dedong H, Zhihui H, Yanpeng Q, Yan L. Preparation of cefquinome nanoparticles by using the supercritical antisolvent process. J Nanomater, 2015;2015:1-6; doi:10.1155/2015/767945

Keraliya RA, Patel C, Patel P, Keraliya V, Soni TG, Patel RC, Patel MM. Osmotic drug delivery system as a part of modified release dosage form. ISRN Pharm, 2012; 2012:1-9; doi:10.5402/2012/528079

Khinast J, Baumgartner R, Roblegg E. Nano-extrusion: a onestep process for manufacturing of solid nanoparticle formulations directly from the liquid phase. AAPS PharmSciTech, 2013; 14:601-4; doi:10.1208/ s12249-013-9946-0

Khosa A, Singhvi G, Saha RN, Gupta G. Drug delivery to the CNS. Panminerva Med, 2018; 60:226; doi:10.23736/S0031-0808.18. 03471-7

Kluge J, Mazzotti M. CO2-assisted high pressure homogenization: a solvent-free process for polymeric microspheres and drug-polymer composites. Int J Pharm, 2012; 436, 394-402; doi:10.1016/j. ijpharm.2012.06.048

Kohli AG, Kierstead PH, VendittoVJ, Walsh CL, Szoka FC Designer lipids for drug delivery: from heads to tails. J Control Release, 2014; 190:274-87; doi:10.1016/j.jconrel.2014.04.047

Koo JS, Lee SY, Nam S, Azad MOK, Kim M, Kim K, Chae BJ, Kang WS, Cho HJ. Preparation of cupric sulfate-based self-emulsifiable nanocomposites and their application to the photothermal therapy of colon adenocarcinoma. Biochem Biophys Res Commun, 2018; 503:2471-7; doi:10.1016/j.bbrc.2018.07.002

Kumar S, Kaur P, Bernela M, Rani R, Thakur R. Ketoconazole encapsulated in chitosan-gellan gum nanocomplexes exhibits prolonged antifungal activity. Int J Biol Macromol, 2016; 93:988-94; doi:10.1016/J. IJBIOMAC.2016.09.042

Kunjachan S, Jose S. Understanding the mechanism of ionic gelation for synthesis of chitosan nanoparticles using qualitative techniques. Asian J Pharm, 2010; 4:148; doi:10.4103/0973-8398.68467

Kwon HY, Lee JY, Choi SW, Jang Y, Kim JH. Preparation of PLGA nanoparticles containing estrogen by emulsification-diffusion method. Colloids Surfaces A Physicochem Eng Asp, 2001; 182:123-30; doi:10.1016/S0927-7757(00)00825-6

Laaksonen T, Liu P, Rahikkala A, Peltonen L, Kauppinen EI, Hirvonen J, Järvinen K, Raula J. Intact nanoparticulate indomethacin in fast-dissolving carrier particles by combined wet milling and aerosol flow reactor methods. Pharm Res, 2011; 28:2403-11; doi:10.1007/s11095-011$0456-\mathrm{z}$

LaManna CM, Lusic H, Camplo M, McIntosh TJ, Barthélémy P, Grinstaff MW. Charge-Reversal Lipids, Peptide-Based Lipids, and Nucleoside-Based Lipids for Gene Delivery. Acc Chem Res, 2012; 45:1026-38; doi:10.1021/ar200228y

Lee S, Nam S, Choi Y, Kim M, Koo J, Chae BJ, Kang WS, Cho HJ, Lee SY, Nam S, Choi Y, Kim M, Koo JS, Chae BJ, Kang WS, Cho HJ. Fabrication and characterizations of hot-melt extruded nanocomposites based on zinc sulfate monohydrate and soluplus. Appl Sci, 2017; 7:902; doi:10.3390/app7090902

Lin YM, Wu JY, Chen YC, Su YD, Ke WT, Ho HO, Sheu MT. In situ formation of nanocrystals from a self-microemulsifying drug delivery system to enhance oral bioavailability of fenofibrate. Int J Nanomedicine, 2011; 6:2445-57; doi:10.2147/IJN.S25339

Loh ZH, Kumar Samanta A, Wan P, Heng S. Overview of milling techniques for improving the solubility of poorly water-soluble drugs. Asian J Pharm Sci, 2015; 10:255-74; doi:10.1016/j.ajps.2014.12.006

Luan J, Zhang D, Hao L, Qi L, Liu X, Guo H, Li C, Guo Y, Li T, Zhang Q, Zhai G. Preparation, characterization and pharmacokinetics of Amoitone B-loaded long circulating nanostructured lipid carriers. Colloids Surfaces B Biointerfaces, 2014; 114:255-60; doi:10.1016/j. colsurfb.2013.10.018

Mahmoudi M, Lynch I, Ejtehadi MR, Monopoli MP, Bombelli FB, Laurent S. Protein-nanoparticle interactions: opportunities and challenges. Chem Rev, 2011; 111:5610-37; doi:10.1021/cr100440g

Maniruzzaman M, Boateng JS, Snowden MJ, Douroumis D. A review of hot-melt extrusion: process technology to pharmaceutical products. ISRN Pharm, 2012; 2012:436763; doi:10.5402/2012/436763

Manouras T, Vamvakaki M. Field responsive materials: photo-, electro-, magnetic- and ultrasound-sensitive polymers. Polym Chem, 2017; 8:74-96; doi:10.1039/C6PY01455K

Martinho N, Damgé C, Reis CP. Recent advances in drug delivery systems. J Biomater Nanobiotechnol, 2011; 02:510-26; doi:10.4236/ jbnb.2011.225062

Mehnert W, Mäder K. Solid lipid nanoparticles: production, characterization and applications. Adv Drug Deliv Rev, 2001; 47: $165-96$.

Mendoza-Muñoz N, Quintanar-Guerrero D, Allémann E. The impact of the salting-out technique on the preparation of colloidal particulate systems for pharmaceutical applications. Recent Pat Drug Deliv Formul, 2012; 6:236-49.

Miller WH, Schipper HM, Lee JS, Singer J, Waxman S Mechanisms of action of arsenic trioxide. Cancer Res, 2002; 62:3893-903.

Mo R, Jiang T, DiSanto R, Tai W, Gu Z. ATP-triggered anticancer drug delivery. Nat Commun, 2014; 5:3364; doi:10.1038/ncomms4364

Moinard-Chécot D, Chevalier Y, Briançon S, Beney L, Fessi H. Mechanism of nanocapsules formation by the emulsion-diffusion process. J Colloid Interface Sci, 2008; 317:458-468; doi:10.1016/j.jcis.2007.09.081

Monopoli MP, Åberg C, Salvati A, Dawson KA. Biomolecular coronas provide the biological identity of nanosized materials. Nat Nanotechnol, 2012; 7:779-86; doi:10.1038/nnano.2012.207

Mora-Huertas CE, Fessi H, Elaissari A. Polymer-based nanocapsules for drug delivery. Int J Pharm, 2010; 385:113-42; doi:10.1016/j.ijpharm.2009.10.018

Müller RH, Petersen RD, Hommoss A, Pardeike J. Nanostructured lipid carriers (NLC) in cosmetic dermal products. Adv Drug Deliv Rev, 2007; 59:522-30; doi:10.1016/J.ADDR.2007.04.012

Murthy SK. Nanoparticles in modern medicine: state of the art and future challenges. Int J Nanomedicine, 2007; 2:129-41.

Nagavarma BVN, Yadav H, Ayaz A, S Vasudha L, G Shivakumar H. Different techniques for preparation of polymeric nanoparticles-a review. Asian J Pharm Clin Res, 2012; 5(3):16-23.

Nakamura Y, Mochida A, Choyke PL, Kobayashi H. Nanodrug delivery: is the enhanced permeability and retention effect sufficient for curing cancer? Bioconjug Chem, 2016; 27:2225-38; doi:10.1021/acs. bioconjchem.6b00437

Naseri N, Valizadeh H, Zakeri-Milani P. Solid lipid nanoparticles and nanostructured lipid carriers: structure, preparation and application. Adv Pharm Bull, 2015; 5:305-13; doi:10.15171/apb.2015.043

Ortega AL, Mena S, Estrela JM. Glutathione in cancer cell death Cancers (Basel), 2011; 3:1285-310; doi:10.3390/cancers3011285

Paliwal R, Babu RJ, Palakurthi S. Nanomedicine scale-up technologies: feasibilities and challenges. AAPS PharmSciTech, 2014; 15:1527-34; doi:10.1208/s12249-014-0177-9

Parhi R, Suresh P, Preparation and characterization of solid lipid nanoparticles-a review. Curr Drug Discov Technol, 2012; 9:2-16.

Patil P, Chavanke daksha WM. A review on ionotropic gelation method: Novel approach for controlled gastroretentive gelispheres. Int J Pharm Pharm, 2012; Sci 4:27-32.

Pelegri-O'Day EM, Maynard HD. Controlled radical polymerization as an enabling approach for the next generation of proteinpolymer conjugates. Acc Chem Res, 2016; 49:1777-85; doi:10.1021/acs. accounts.6b00258

Pinjari DV, Prasad K, Gogate PR, Mhaske ST, Pandit AB. Synthesis of titanium dioxide by ultrasound assisted sol-gel technique: 
effect of calcination and sonication time. Ultrason Sonochem, 2015; 23:185-91; doi:10.1016/j.ultsonch.2014.10.017

Pinto Reis C, Neufeld RJ, Ribeiro AJ, Veiga F, Nanoencapsulation I. Methods for preparation of drug-loaded polymeric nanoparticles. Nanomed Nanotechnol Biol Med, 2006; 2:8-21; doi:10.1016/j.nano.2005.12.003

Pradhan S, Hedberg J, Blomberg E, Wold S, Odnevall Wallinder

I. Effect of sonication on particle dispersion, administered dose and metal release of non-functionalized, non-inert metal nanoparticles. J Nanopart Res, 2016; 18:285; doi:10.1007/s11051-016-3597-5

Rajaonarivony M, Vauthier C, Couarraze G, Puisieux F, Couvreur P. Development of a new drug carrier made from alginate. J Pharm Sci, 1993; 82:912-7; doi:10.1002/jps.2600820909

Ramalingam P, Yoo SW, Ko YT. Nanodelivery systems based on mucoadhesive polymer coated solid lipid nanoparticles to improve the oral intake of food curcumin. Food Res Int, 2016; 84:113-9; doi:10.1016/j. foodres.2016.03.031

Ramasamy T, Tran TH, Choi JY, Cho HJ, Kim JH, Yong CS, Choi HG, Kim JO. Layer-by-layer coated lipid-polymer hybrid nanoparticles designed for use in anticancer drug delivery. Carbohydr Polym, 2014; 102:653-61; doi:10.1016/j.carbpol.2013.11.009

Ranpise NS, Korabu SS, Ghodake VN. Second generation lipid nanoparticles (NLC) as an oral drug carrier for delivery of lercanidipine hydrochloride. Colloids Surfaces B Biointerfaces, 2014; 116:81-7; doi:10.1016/j.colsurfb.2013.12.012

Rapalli VK, Singhvi G, Dubey SK, Gupta G, Chellappan DK, Dua K. Emerging landscape in psoriasis management: from topical application to targeting biomolecules. Biomed Pharmacother, 2018; 106:707-13; doi:10.1016/j.biopha.2018.06.136

Roy R, Yang J, Moses MA. Matrix metalloproteinases as novel biomarkers and potential therapeutic targets in human cancer. J Clin Oncol, 2009; 27:5287-97; doi:10.1200/JCO.2009.23.5556

Safari J, Zarnegar Z. Advanced drug delivery systems: nanotechnology of health design A review. J Saudi Chem Soc, 2014; 18:8599; doi:10.1016/J.JSCS.2012.12.009

Sangwai M, Vavia P. Amorphous ternary cyclodextrin nanocomposites of telmisartan for oral drug delivery: improved solubility and reduced pharmacokinetic variability. Int J Pharm, 2013; 453:423-32; doi:10.1016/j.ijpharm.2012.08.034

Sanli D, Bozbag SE, Erkey C. Synthesis of nanostructured materials using supercritical $\mathrm{CO}_{2}$ : part I. Physical transformations. J Mater Sci, 2012; 47:2995-3025; doi:10.1007/s10853-011-6054-y

Sarmento B, Ribeiro AJ, Veiga F, Ferreira DC, Neufeld RJ. Insulin-loaded nanoparticles are prepared by alginate ionotropic pregelation followed by chitosan polyelectrolyte complexation. J Nanosci Nanotechnol, 2007; 7, 2833-41.

Scalia S, Franceschinis E, Bertelli D, Iannuccelli V. Comparative evaluation of the effect of permeation enhancers, lipid nanoparticles and colloidal silica on in vivo human skin penetration of quercetin. Skin Pharmacol Physiol, 2013; 26:57-67; doi:10.1159/000345210

Schubert S, Delaney Jr JT, Schubert US. Nanoprecipitation and nanoformulation of polymers: from history to powerful possibilities beyond poly(lactic acid). Soft Matter, 2011; 7:1581-8; doi:10.1039/C0SM00862A

Seedat N, Kalhapure RS, Mocktar C, Vepuri S, Jadhav M, Soliman M, Govender T. Co-encapsulation of multi-lipids and polymers enhances the performance of vancomycin in lipid-polymer hybrid nanoparticles: In vitro and in silico studies. Mater Sci Eng C, 2016; 61:61630; doi:10.1016/j.msec.2015.12.053

Shi F, Yang G, Juan Ren J, Guo T, Du Y, Feng N. Formulation design, preparation, and in vitro and in vivo characterizations of \&amp; beta;Elemene- loaded nanostructured lipid carriers. Int J Nanomedicine, 2013; 8:2533; doi:10.2147/IJN.S46578

Shi LE, Fang XJ, Zhang ZL, Zhou T, Jiang D, Wu HH, Tang ZX. Preparation of nano-ZnO using sonication method and its antibacterial characteristics. Int J Food Sci Technol; 2012; 47:1866-71; doi:10.1111/ j.1365-2621.2012.03043.x

Singhvi G, Banerjee S, Khosa A. Lyotropic liquid crystal nanoparticles: a novel improved lipidic drug delivery system. Org Mater as
Smart Nanocarriers Drug Deliv, 2018; 471-517; doi:10.1016/B978-0-12813663-8.00011-7

Sivaram AJ, Wardiana A, Howard CB, Mahler SM, Thurecht KJ Recent Advances in the Generation of Antibody-Nanomaterial Conjugates Adv Healthc Mater, 2018; 7:1700607; doi:10.1002/adhm.201700607

Skorik YA, Golyshev AA, Kritchenkov AS, Gasilova ER, Poshina DN, Sivaram AJ, Jayakumar R. Development of drug delivery systems for taxanes using ionic gelation of carboxyacyl derivatives of chitosan Carbohydr Polym, 2017; 162:49-55; doi:10.1016/j.carbpol.2017.01.025

Song D, Thio YS, Deng Y. Starch nanoparticle formation via reactive extrusion and related mechanism study. Carbohydr Polym, 2011; 85:208-14; doi:10.1016/J.CARBPOL.2011.02.016

Tian Y, Jiang X, Chen X, Shao Z, Yang W. Doxorubicin-loaded magnetic silk fibroin nanoparticles for targeted therapy of multidrug-resistant cancer. Adv Mater, 2014; 26:7393-8; doi:10.1002/adma.201403562

Tolbert SH, McFadden PD, Loy DA. New hybrid organic/ inorganic polysilsesquioxane-silica particles as sunscreens. ACS Appl Mater Interfaces, 2016; 8:3160-74; doi:10.1021/acsami.5b10472

Tran TH, Ramasamy T, Truong DH, Choi HG, Yong CS, Kim JO. Preparation and characterization of fenofibrate-loaded nanostructured lipid carriers for oral bioavailability enhancement. AAPS PharmSciTech, 2014; 15:1509-15; doi:10.1208/s12249-014-0175-y

Uprit S, Kumar Sahu R, Roy A, Pare A. Preparation and characterization of minoxidil loaded nanostructured lipid carrier gel for effective treatment of alopecia. Saudi Pharm J, 2013; 21:379-85; doi:10.1016/j.jsps.2012.11.005

Waghule T, Rapalli VK, Singhvi G, Manchanda P, Hans N, Dubey SK, Hasnain MS, Nayak AK. Voriconazole loaded nanostructured lipid carriers based topical delivery system: QbD based designing, characterization, in-vitro and ex-vivo evaluation. J Drug Delivery Sci Technol, 2019; 52:303-15; doi:10.1016/j.jddst.2019.04.026

Wang J, Ma Q, Wang Y, Shen H, Yuan Q. Recent progress in biomedical applications of persistent luminescence nanoparticles Nanoscale, 2017; 9:6204-18; doi:10.1039/c7nr01488k

Wang X, Liu D, Li J, Zhen J, Wang F, Zhang H. $\gamma$-Al ${ }_{2} \mathrm{O}_{3}$ supported Pd@CeO core@shell nanospheres: salting-out assisted growth and self-assembly, and their catalytic performance in $\mathrm{CO}$ oxidation. Chem Sci, 2015; 6:2877-84; doi:10.1039/C4SC03854A

Wei A, Mehtala JG, Patri AK. Challenges and opportunities in the advancement of nanomedicines. J Control Release, 2012; 164:236-46; doi:10.1016/j.jconrel.2012.10.007

Xie H, Smith JW. Fabrication of PLGA nanoparticles with a fluidic nanoprecipitation system. J Nanobiotechnology, 2010; 8:18; doi:10.1186/1477-3155-8-18

Yameen B, Choi W Il, Vilos C, Swami A, Shi J, Farokhzad OC. Insight into nanoparticle cellular uptake and intracellular targeting. J Control Release, 2014; 190:485-99; doi:10.1016/j.jconrel.2014.06.038

Yang X, Zhao L, Almasy L, Garamus VM, Zou A, Willumeit R, Fan S. Preparation and characterization of 4-dedimethylamino sancycline (CMT-3) loaded nanostructured lipid carrier (CMT-3/NLC) formulations. Int J Pharm, 2013; 450:225-34; doi:10.1016/j.ijpharm.2013.04.021

Ye Y, Zhang X, Zhang T, Wang H, Wu B. Design and evaluation of injectable niclosamide nanocrystals prepared by wet media milling technique. Drug Dev Ind Pharm, 2015; 41:1416-24; doi:10.3109/036390 45.2014.954585

Zeng W, Li Q, Wan T, Liu C, Pan W, Wu Z, Zhang G, Pan J, Qin M, Lin Y, Wu C, Xu Y. Hyaluronic acid-coated niosomes facilitate tacrolimus ocular delivery: mucoadhesion, precorneal retention, aqueous humor pharmacokinetics, and transcorneal permeability. Colloids Surfaces B Biointerfaces, 2016; 141:28-35; doi:10.1016/j. colsurfb.2016.01.014

Zhang K, Lv S, Li X, Feng Y, Li X, Liu L, Li S, Li Y. Preparation, characterization, and in vivo pharmacokinetics of nanostructured lipid carriers loaded with oleanolic acid and gentiopicrin. Int J Nanomedicine, 2013a; 8:3227; doi:10.2147/IJN.S45031

Zhang XY, Qiao H, Ni JM, Shi YB, Qiang Y. Preparation of isoliquiritigenin-loaded nanostructured lipid carrier and the in vivo 
evaluation in tumor-bearing mice. Eur J Pharm Sci, 2013b; 49:411-22; doi:10.1016/j.ejps.2013.04.020

Zhao C, Fan T, Yang Y, Wu M, Li L, Zhou Z, Jian Y, Zhang Q, Huang Y. Preparation, macrophages targeting delivery and antiinflammatory study of pentapeptide grafted nanostructured lipid carriers. Int J Pharm, 2013; 450:11-20; doi:10.1016/j.ijpharm.2013.04.030

Zhao P, Zheng M, Yue C, Luo Z, Gong P, Gao G, Sheng Z, Zheng C, Cai L. Improving drug accumulation and photothermal efficacy in tumor depending on size of ICG loaded lipid-polymer nanoparticles. Biomaterials, 2014; 35:6037-46; doi:10.1016/j.biomaterials.2014.04.019

Zhao Y, Bai T, Shao Q, Jiang S, Shen AQ. Thermoresponsive self-assembled NiPAm-zwitterion copolymers. Polym Chem, 2015; 6:1066-77; doi:10.1039/C4PY01553C
Zhou L, Chen Y, Zhang Z, He J, Du M, Wu Q. Preparation of tripterine nanostructured lipid carriers and their absorption in rat intestine. Pharmazie, 2012; 67:304-10.

How to cite this article:

Jain S, Cherukupalli SK, Mahmood A, Gotantla S, Rapalli

VK, Dubey SK, Singhvi G. Emerging nanoparticulate systems: Preparation techniques and stimuli responsive release characteristics. J Appl Pharm Sci, 2019; 9(08): 130-143. 